\title{
Climatology of daily rainfall semi-variance in The Netherlands
}

\author{
C. Z. van de Beek, H. Leijnse, P. J. J. F. Torfs, and R. Uijlenhoet
}

Hydrology and Quantitative Water Management Group, Department of Environmental Sciences, Wageningen University, Wageningen, The Netherlands

Received: 22 February 2010 - Published in Hydrol. Earth Syst. Sci. Discuss.: 24 March 2010

Revised: 5 November 2010 - Accepted: 14 December 2010 - Published: 18 January 2011

\begin{abstract}
Rain gauges can offer high quality rainfall measurements at their locations. Networks of rain gauges can offer better insight into the space-time variability of rainfall, but they tend to be too widely spaced for accurate estimates between points. While remote sensing systems, such as radars and networks of microwave links, can offer good insight in the spatial variability of rainfall they tend to have more problems in identifying the correct rain amounts at the ground. A way to estimate the variability of rainfall between gauge points is to interpolate between them using fitted variograms. If a dense rain gauge network is lacking it is difficult to estimate variograms accurately. In this paper a 30year dataset of daily rain accumulations gathered at 29 automatic weather stations operated by KNMI (Royal Netherlands Meteorological Institute) and a one-year dataset of 10 gauges in a network with a radius of $5 \mathrm{~km}$ around CESAR (Cabauw Experimental Site for Atmospheric Research) are employed to estimate variograms. Fitted variogram parameters are shown to vary according to season, following simple cosine functions. Semi-variances at short ranges during winter and spring tend to be underestimated, but semi-variances during summer and autumn are well predicted.
\end{abstract}

\section{Introduction}

Rainfall is highly variable both in time and space and accurate measurements are important in hydrology (Bell and Moore, 2000; Arnaud et al., 2002; Tetzlaff and Uhlenbrook, 2005). Especially in urban settings where the response time of runoff is typically very short these accurate estimates are needed (Smith et al., 2002, 2005; Vaes, 2005; Olsson et al.,

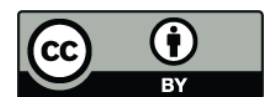

Correspondence to: C. Z. van de Beek (remco.vandebeek@wur.nl)
2009; Villarini et al., 2010). There are several instruments available to measure these rainfall distributions. The traditional instrument to measure rainfall is the rain gauge. While rain gauges measure rain accurately and continuously at a point, they offer little information on rainfall between gauges. Rain gauges themselves are not fully accurate and are influenced by factors such as calibration accuracy, wind effects and sampling uncertainty, which also limits the accuracy for sampling intervals smaller than $10 \mathrm{~min}$ (Humphrey et al., 1997; Calder and Kidd, 1978; Marsalek, 1981; Habib et al., 2001; Ciach, 2003; Sieck et al., 2007). Frozen precipitation like snow and hail also offers a problem as these hydro-meteors do not melt immediately and therefore will result in a lower precipitation rate estimate over a longer period than actually occurred.

Other measurements with instruments like microwave links (Leijnse et al., 2007) and disdrometers (Joss and Waldvogel, 1977) offer alternative methods for measuring rainfall, but are more expensive and do not measure the spatial variability for an entire catchment area. Weather radars are able to measure spatial variability of rainfall at different spatial resolutions depending on wavelength and antenna size and measure at typical intervals of 5 to $15 \mathrm{~min}$ for ground based systems and with an interval of $3 \mathrm{~h}$ or more for satellites (e.g. Uijlenhoet, 2008). Quantifying these rainrate measurements is non-trivial as the reflected signal of a volume in the air has to be transformed into an accurate estimate of rainfall at the ground. It requires knowledge of the microstructure and the vertical variation of rainfall, which is generally not available. Furthermore, a good calibration of the radar system itself and correction of factors such as attenuation and ground clutter are important for accurate radar rainfall estimation (Hitschfeld and Bordan, 1954; Marshall et al., 1955; Marzoug and Amayenc, 1994; Delrieu et al., 1999; Krajewski and Smith, 2002; Villarini and Krajewski, 2010; van de Beek et al., 2010).

Published by Copernicus Publications on behalf of the European Geosciences Union. 
There are many examples of studies into the optimal sampling density and interval for these instruments (Villarini et al., 2008; Villarini and Krajewski, 2008; Nour et al., 2006; Cheng et al., 2008). The variability of rainfall both in space and time has also been studied extensively, mainly using rain gauge and radar data (Ensor and Scott, 2008; Krajewski et al., 2000; Berne et al., 2004b; Knox and Anagnostou, 2009; Habib et al., 2009). Rainfall variability has also been investigated in The Netherlands (Buishand and Velds, 1980; Witter, 1984; Schuurmans et al., 2007), where focus in the last few years has been on extremes for water management and possible changes in climate. Buishand et al. (2008), using 30 years of data of 32 rainguages in the province of Noord Holland, The Netherlands investigate the amount of daily rainfall for an extreme once-in-100-years event. This work is continued by Buishand et al. (2009), using the daily rain sums of 141 stations in The Netherlands between 1951 and 2005 to find the regional rainfall differences using generalized extreme value distributions (GEV). They identify 4 different precipitation regimes in The Netherlands. Overeem et al. (2009) use the rainfall data of 12 stations to create a 514 year record. A GEV is fitted to this data for durations between 1 and $24 \mathrm{~h}$ and used to construct depth-durationfrequency (DDF) curves. Using a bootstrap method the uncertainty of these DDFs is estimated.

The goal of this study is to produce a simple equation to estimate the daily rainfall variogram as a function of the time of year. This allows the creation of areal rainfall maps for hydrological modeling purposes at smaller catchment scales where often only one or very few gauges are available to estimate rainfall amount and distribution. For hydrological modeling variograms are often used in the creation of rainfall maps by interpolating sparse rain gauge data using kriging (Creutin et al., 1986; Krajewski, 1987; Papamichail and Metaxa, 1996; Nour et al., 2006; Haberlandt, 2007; Kirstetter et al., 2010). Kriging of the data has the advantage that the associated variance for each estimated location can be obtained. The associated uncertainty of the estimated areal rainfall found from the kriging variance can be used as input in a hydrological model and offers a better understanding of the upper and lower margins of the estimated discharge. The estimated variograms also offer a way of generating random fields for research purposes (Cressie, 1993; Diggle and Ribeiro Jr., 2007; Li et al., 2008).

The data used is this study are 30 years of daily rainfall data as well as one year of high-resolution gauge network data. In Sect. 2 the data and study area are described. The theory is described in Sect. 3. Section 4 concerns the methods used to estimate the seasonal variograms and Sect. 5 describes the results. Finally Sect. 6 summarizes the study and offers recommendations for future work.

\section{Study area and data}

In The Netherlands the rain maximum typically occurs around November with a rain sum between 60 and $100 \mathrm{~mm}$ during this month. The minimum occurs around April with around $40-60 \mathrm{~mm}$. The yearly rain sum lies around $800 \mathrm{~mm}$. While The Netherlands is fairly small, with a land surface area of less than $34000 \mathrm{~km}^{2}$, differences in yearly rainfall between locations can be up to $200 \mathrm{~mm}$ (source: $\mathrm{KNMI}^{1}$ ).

\subsection{KNMI station data}

Data from 33 automatic KNMI stations between 1 January 1979 and 15 February 2009 were considered for this study (top panel Fig. 1). They offer a good way to evaluate larger scale variation of rainfall. Their distribution is shown in Fig. 2, with an average inter-gauge distance of $120 \mathrm{~km}$. One-day rainfall accumulations are used for the climatological study in this paper. The hourly accumulations are available with a volumetric resolution of $0.1 \mathrm{~mm}$. Nonzero rainfall accumulations below $0.05 \mathrm{~mm}$ have been set to $0.05 \mathrm{~mm}$ in this dataset to indicate nonzero rain (this would otherwise be rounded to zero). While rounding these measured data to $0.05 \mathrm{~mm}$ might lead to some slight overestimations this was chosen to be preferable by the authors as now all rainfall is included. Data of the KNMI volunteer network with 329 locations of daily rainfall accumulations were also considered. Because of errors introduced by observers (Daly et al., 2007), causing high variance for data pairs located close to each other, it was decided that this dataset was not suitable for this study. The accuracy of these gauges is described in Wauben (2006) and the history of each individual gauge can be found at the KNMI site at http://www.knmi.nl/klimatologie/metadata.

\subsection{Dense rain gauge network}

The second dataset was collected using a dense network of 30 tipping-bucket rain gauges around CESAR (Cabauw Experimental Site for Atmospheric Research) which were jointly operated by University of Utrecht and Wageningen University (Schuurmans et al., 2007; Leijnse et al., 2010). The gauges had a volumetric resolution of $0.2 \mathrm{~mm}$ and a time resolution of $0.5 \mathrm{~s}$ and were placed within a $5 \mathrm{~km}$ radius around CESAR (bottom panel of Fig. 1). Of this dataset 10 gauges were selected as they operated well and continuously between March 2004 and March 2005. The data were converted to one day accumulations for this study by estimating the rain rate from the number of tips per day. Periods of $6 \mathrm{~h}$ or longer without a tip were assumed to be dry. The resulting data are used for estimating the short range rainfall variation for the detailed one-year study.

\footnotetext{
${ }^{1}$ http://www.knmi.nl/klimatologie/normalen1971-2000/index. html
} 

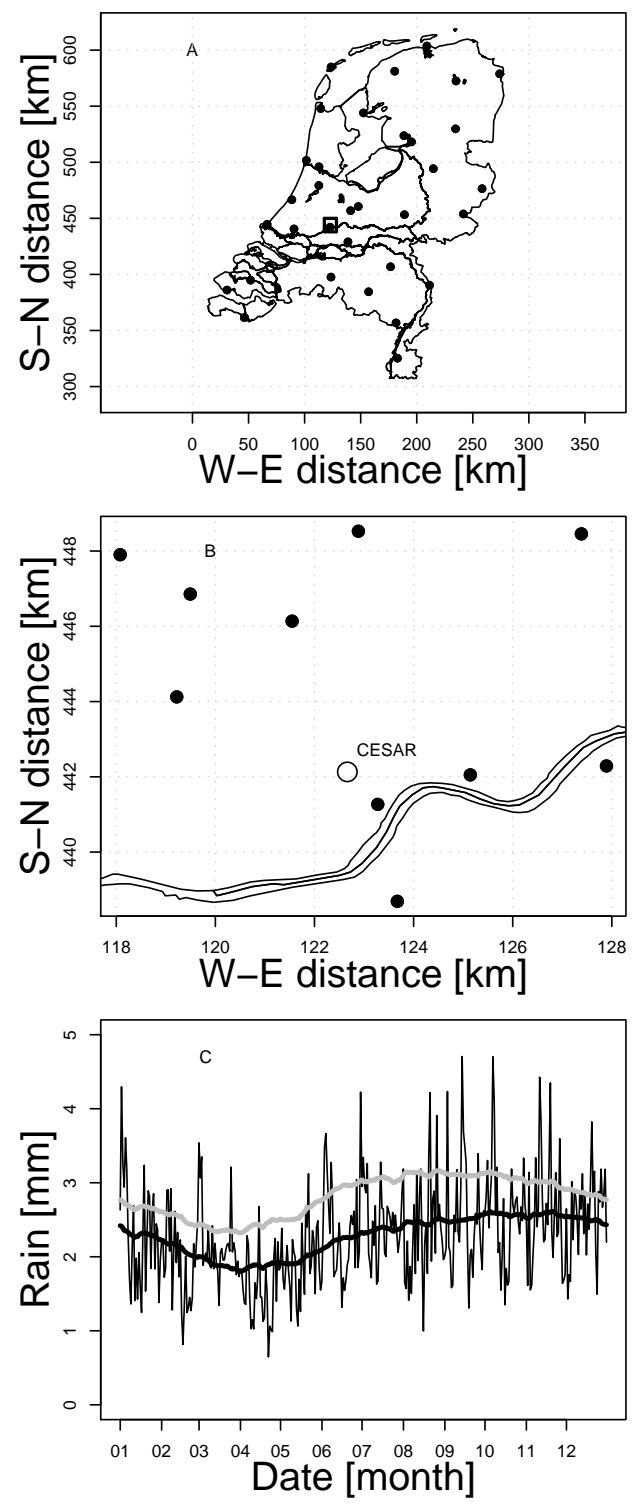

Fig. 1. (A) station locations of the $33 \mathrm{KNMI}$ measurement stations. The square near the centre of The Netherlands is shown in $(\mathbf{B})$ and is a detail of the 10 selected gauges of the dense gauge network. (C) The 30-year mean rainfall in The Netherlands, where the thin black line is the average rainfall for each day, the thick black line the 90-day moving average and the thick grey line the 90-day moving average for rainfall events only (i.e. with dry days excluded).

\section{Theory}

A standard method for evaluating rainfall variability is to estimate variograms. Assuming stationarity and isotropy of the rainfall field, which is not an unreasonable assumption on the daily scale, the experimental omnidirectional semivariogram can be found by taking half the average of the squared difference between data pairs within the same distance interval (Cressie, 1993):

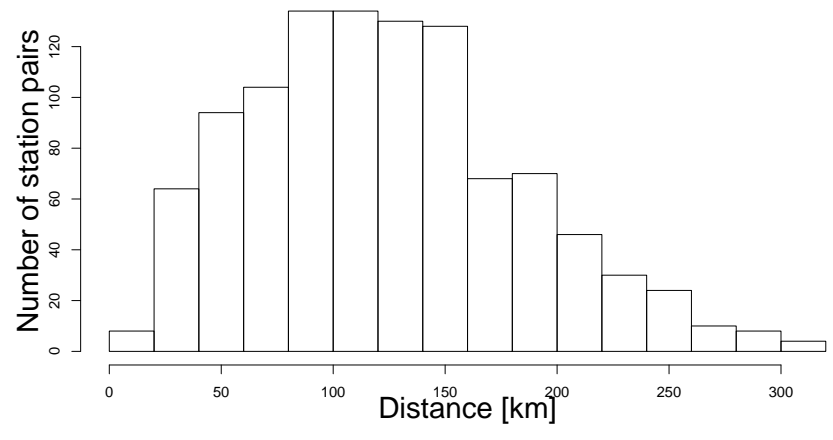

Fig. 2. Histogram of the distance between the KNMI automatic rain gauges.

$\hat{\gamma}(|h|)=\frac{1}{2 n(|h|)} \sum_{i=1}^{n(|h|)}\left(z\left(x_{i}+h\right)-z\left(x_{i}\right)\right)^{2}$,

where $x_{i}$ is the location of gauge $i$ and $x_{i}+h$ the locations at distance $h$ from location $x_{i}$. For a dataset with measurements at $n$ locations this means there are $n(n-1) / 2$ data pairs with different separation distances, i.e. 528 pairs for the nationwide network and 45 pairs for the dense network. Rainfall anisotropy has been studied extensively in the past (Guillot and Lebel, 1999; Velasco-Forero et al., 2009; Schleiss et al., 2009). While anisotropy is always an issue with rainfall the effects are reduced by the averaging over 90 days. Another reason is that we want to keep the number of parameters as low as possible to maintain a simple model. If too many parameters are included they might become interdependent and a sound statistical analysis would become highly complicated. For a sound analysis of possible anisotropy and stationarity a more extensive dataset would be needed and inclusion from the Belgian and German network might offer interesting future research.

As the empirical variogram values will not offer values for each distance $h$ one of several possible models has to be fitted to estimate these semi-variances. While many types, like exponential, Gaussian or logarithmic exist (Diggle and Ribeiro Jr., 2007) it was decided to take a simple spherical variogram as this model adequately fits the variogram values with only a few parameters, unlike more complex models where the parameters can become highly complicated to interpret (Berne et al., 2004b):

$\gamma(h)=\left\{\begin{array}{lll}c_{0}+c_{1}\left(\frac{3}{2} \frac{h}{a}-\frac{1}{2}\left(\frac{h}{a}\right)^{3}\right) & \text { if } & h \leq a \\ c_{0}+c_{1} & \text { if } & h>a\end{array}\right.$

Here $c_{0}$ is the nugget (the semi-variance at zero distance), $c_{1}$ is the sill (the maximum value of the fitted semi-variance function) and $a$ is the range (distance at which data pairs are completely decorrelated). See Fig. 3 for an illustration.

As the semi-variance for two gauges from the dense gauge network at a distance of $8 \mathrm{~m}$ using a 90-day moving window was found to be only $0.035 \mathrm{~mm}^{2}$ with a standard deviation 


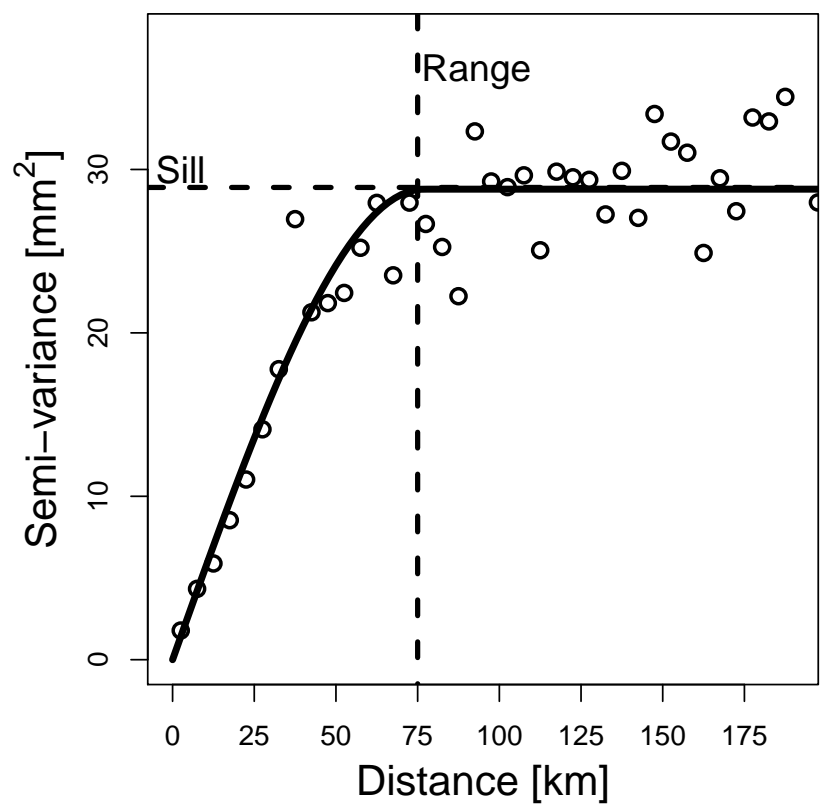

Fig. 3. Example of variogram parameters based on actual data, where the circles represent the binned semi-variance. The solid line is the fitted spherical variogram. The horizontal dashed line is the sill and the vertical dashed line is the range.

$(\sigma)$ of $0.018 \mathrm{~mm}^{2}$, the nugget was assumed negligible and therefore Eq. (2) reduces to:

$\gamma(h)=\left\{\begin{array}{lll}c_{1}\left(\frac{3}{2} \frac{h}{a}-\frac{1}{2}\left(\frac{h}{a}\right)^{3}\right) & \text { if } & h \leq a \\ c_{1} & \text { if } & h>a\end{array}\right.$

which only depends on the sill and range. The spherical variogram near zero distance is approximately linear. This means that for $h \ll a$ the equation can be reduced to:

$\gamma(h)=\frac{3}{2} \frac{c_{1}}{a} h$

\section{Methodology}

The data are analyzed by estimating the daily omnidirectional semi-variance and subsequently averaging these over 90-days using the fitting method described in Chapter 5 of Diggle and Ribeiro Jr. (2007). The weights are equal for each day and the day of interest is taken at the center of the period. To find a signal in the fitted variogram parameters it is necessary to average over an optimal range of days to avoid the noise of day-to-day variations. It was decided to average over 90 days to avoid shorter periods without rainfall, e.g. early spring 2007 with a total of 45 dry days. In addition, as 90 days is the length of a season it is an appropriate length for the purpose of this study.

Even though other weights like a Gaussian or triangular distribution might be used, to keep the fit simple, the window has equal weights for the entire 90-day period, which is in line with the idea of this study to create a simple method of modeling daily variograms. The effect of using triangular weights has been tested and was found to have very little effect. An averaging window of 60 days was also tested and was found to differ very little from the 90-day averaging window.

Finally, the data are binned in distance classes with a $5 \mathrm{~km}$ class width for both faster fitting of the spherical variogram and easier interpretation of the figures. With the furthest gauge pair in the dataset at $315 \mathrm{~km}$ it was decided to set the maximum range at $200 \mathrm{~km}$ for fitting the spherical variogram. Cases where the range is apparently larger than this maximum distance occur mostly around November, when the variogram data tends to be nearly linear over the full domain from 0 to $315 \mathrm{~km}$. In cases like this, where $|h|$ is always smaller than the estimated range of the variogram, Eq. (4) becomes valid.

In Sect. 5 the climatological data will be assessed to find the daily trend in the sill and range. To fit a cosine function to this trend spectral analysis is applied. A simple time-series of a cosine function could be expressed as:

$x_{t}=x_{0}+A \cos \left(2 \pi f\left(t-t_{0}\right)\right)$

Here $x_{0}$ is the offset, $A$ is the amplitude, $f$ is the frequency and $t_{0}$ defines the start day of the cosine function (Shumway and Stoffer, 2006).

\section{Results and discussion}

With rainfall being highly variable both in time and space it is difficult to model the process accurately. In this section it will be shown that there are stable factors in rainfall variability, which can be used for hydrological purposes. The climatological analysis is applied to the KNMI gauges for the 30-year period between January 1979 and February 2009.

\subsection{Climatological variation of rainfall}

While there can be a strong day-to-day fluctuation of rain, a seasonal trend can be found. This is shown in Fig. 4, where the variation of the daily rain accumulation is assessed by taking the average of the data from the $33 \mathrm{KNMI}$ stations and using a 90-day averaging window. In Fig. 4a the mean rain sum can be seen to fluctuate strongly and it is difficult to find a clear trend in the data. While the seasonal signal is the strongest there are very strong deviations from the estimated cosine function and therefore the mean rain sum is difficult to capture in a single function.

For the standard deviation $(\sigma)$ of rainfall between the stations the signal already becomes much clearer (see Fig. 4 b). While there are still departures of more than a factor of two from the fitted cosine the seasonality is clear. This can be explained by the more convective type of rain during summer with more localized events and the more common stratiform 

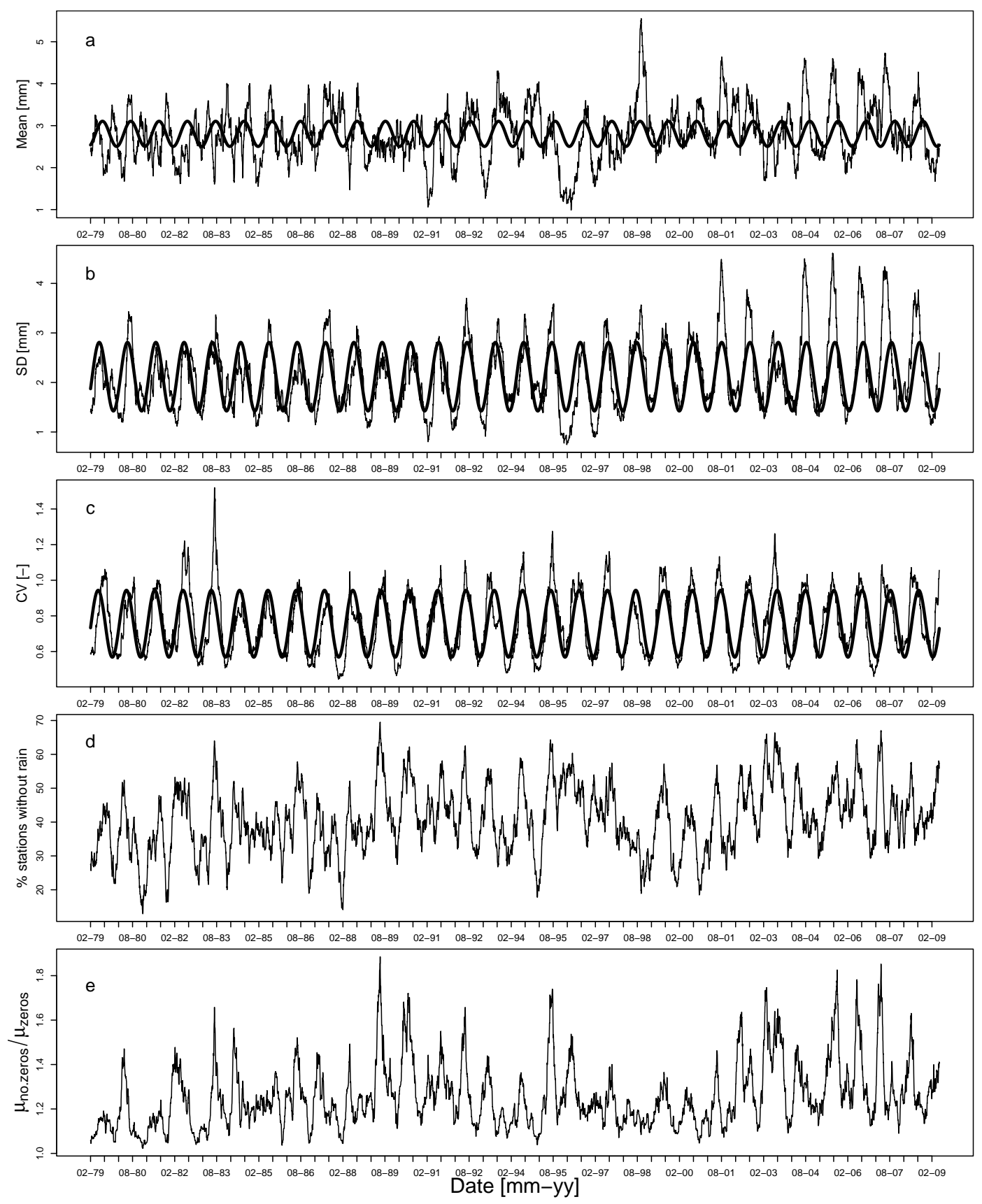

Fig. 4. Temporal variation of rainfall spatial statistics, determined using a 90-day moving window. (a) is the 90-day moving average of the daily rainfall sum. (b) is the average standard deviation for a 90-day moving window. (c) is the coefficient of variation. Bold lines are cosines fitted through the data. (d) is the 90-day moving average of the percentage of dry stations. (e) is the ratio of the mean without dry stations and the mean with dry stations included.

rain type during winter months. The rainfall climate of The Netherlands is such that total rainfall amounts are approximately constant throughout the year. However, the spatial variation is governed by storm type, which does show clear temporal variation in The Netherlands. Finally, a good way to express the relative variation of rainfall is by dividing the standard deviation by the mean to find the coefficient of variation (see Fig. 4c). The fitted simple cosine function can be seen to follow the seasonal variation in the coefficient of variation $(\mathrm{CV})$ very closely. The values found for the fitted functions for mean, $\sigma$ and $\mathrm{CV}$ can be found in Table 1 with $t$ expressed as Day of Year (DOY) and $x_{0}$ the mean of the data. 
Table 1. Parameters of the fitted cosine functions for mean, standard deviation $(\sigma)$ and coefficient of variation $(\mathrm{CV})$ of the daily rain sums of the KNMI stations between 15 February 1979 and 15 February 2009 using a 90 day moving averaging window.

\begin{tabular}{lcrrr}
\hline & $1 / f$ & $A$ & $t_{0}$ & $x_{0}$ \\
\hline mean & 365 & 0.30 & 109.9 & 2.80 \\
$\sigma$ & 365 & 0.69 & 68.2 & 2.12 \\
$\mathrm{CV}$ & 365 & 0.48 & 54.4 & 1.67 \\
\hline
\end{tabular}

The amount of stations with no rainfall measured also has an impact on the statistical distribution of the data. In Fig. 4d the fraction of stations without rainfall is shown, again using a 90-day moving average. The lows in this figure coincide with the lows in the $\sigma$, as could be expected with lower values of $\sigma$ corresponding to more widespread rain, leading to less zeros present in the data. Figure 4e shows the 90-day moving mean with dry locations removed (as shown in Fig. 4a) divided by the moving mean including the stations with zero rainfall. Again the peaks can be found during the summer and lows during winter. With the more localized rainfall occurring during summer the effect of removing the zero rainfall locations from the data is larger during this season than during winter. Due to this effect the mean during summer can be up to 1.8 times larger if zeros are not included, while the ratio during winter is fairly constant (around 1.2).

\subsection{Variogram fitting on climatological data}

With spherical variograms fitted to the 30-year climatological rain data as described in Sect. 3 it is possible to find the seasonal variation of sill and range. We will also investigate the root mean square errors between the 90-day averaged variograms and the corresponding fit. Again frequency analysis is applied to find the best fit for the cosine function to describe the seasonal variation using the rain data with dry locations excluded. This was also tested with dry locations included. While this gave slightly different values this effect was found to be negligible.

\subsubsection{Seasonal range}

As mentioned before, rainfall is strongly seasonal and this also applies to the range of the fitted variograms. The range reaches a minimum in July and a maximum in January (see Fig. 5a). Again this can be attributed to the prevailing rain types during winter and summer. During summer the rain tends to be convective, which means that the correlation quickly decreases with the distance between two points. In winter this changes with stratiform rain, where rain rates can be similar over long distances. There are cases where the fitted range is far beyond $200 \mathrm{~km}$ and thus even beyond the furthest data pair at $315 \mathrm{~km}$ and therefore not reliable. This causes the fitted variogram to be nearly linear up to $200 \mathrm{~km}$ distance, in line with what could be expected from Eq. (4). This is caused by the large-scale stratiform precipitation that is common during this time of the year. As the range at these times is far beyond the furthest data pair, because of a linear instead of a spherical relation, the estimation of the range and sill would add little meaning and therefore the maximum range was set to $300 \mathrm{~km}$.

A square-root square-root (sqrt-sqrt) transform was applied to the fitted range values. There are numerous other possible transforms like logarithmic, logistic and Box-Cox (Shumway and Stoffer, 2006; Hartwig and Dearing, 1979), but the sqrt-sqrt transform was chosen to try to reduce the influence of extreme values for a better fit of the cosine function as well as making the resulting distribution more symmetrical (see Fig. 6a and b). The cutoff of the histograms at the right hand side is caused by the maximum range of $300 \mathrm{~km}$. The resulting fit can be modeled as:

$x_{t}=\left[x_{0}+A \cos \left(2 \pi f\left(t-t_{0}\right)\right)\right]^{4}$

This model is the same as Eq. (5) but transformed with a power 4 (the inverse sqrt-sqrt transform). This transform has only a slight effect for the range as can be seen in Fig. 6a, but it is applied so the results are in line with that of the sill, where the transform does have a large effect, as shown in Sect. 5.2.2. While the fit is not perfect, the seasonal effect is followed quite well. Most of the strong differences occur in November when the variogram is more often linear than spherical. The values for this fit can be found in Table 2 .

Another way to look at the fit is to take the average for each day of the year (DOY) of those 30 years. As shown in Fig. 7a, this results again in a clear seasonal trend. The solid line is the average of the estimated ranges from the 90-day moving window spherical variograms, but with all ranges larger than $300 \mathrm{~km}$ removed. The dashed lines are the climatological fits through the 30 year data, which follows the average rather well. The exception to the smooth cosine of the climatological fit is around November and December, when the semivariance tends to become more linear than spherical and the range therefore becomes larger than $300 \mathrm{~km}$. The slight low here is due to the fact that when the range is linear beyond $300 \mathrm{~km}$ the data is filtered and remaining spherical fits tend to have fairly short ranges, which influences the average.

\subsubsection{Seasonal sill}

Like the range in the previous section, the seasonality is clearly apparent for the sill of the fitted variograms (Fig. 5b). The sill data were again sqrt-sqrt transformed and fitted to the cosine model of Eq. (6). The corresponding values are found in Table 2.

Similar to the range in Fig. 7a the average sill is also plotted as a function of the time of year. Figure $7 \mathrm{~b}$ shows the results, where the solid line is the sill (with all values where the range was more than $300 \mathrm{~km}$ removed) and the dashed lines are the climatological fits. Again the seasonality is clear. 

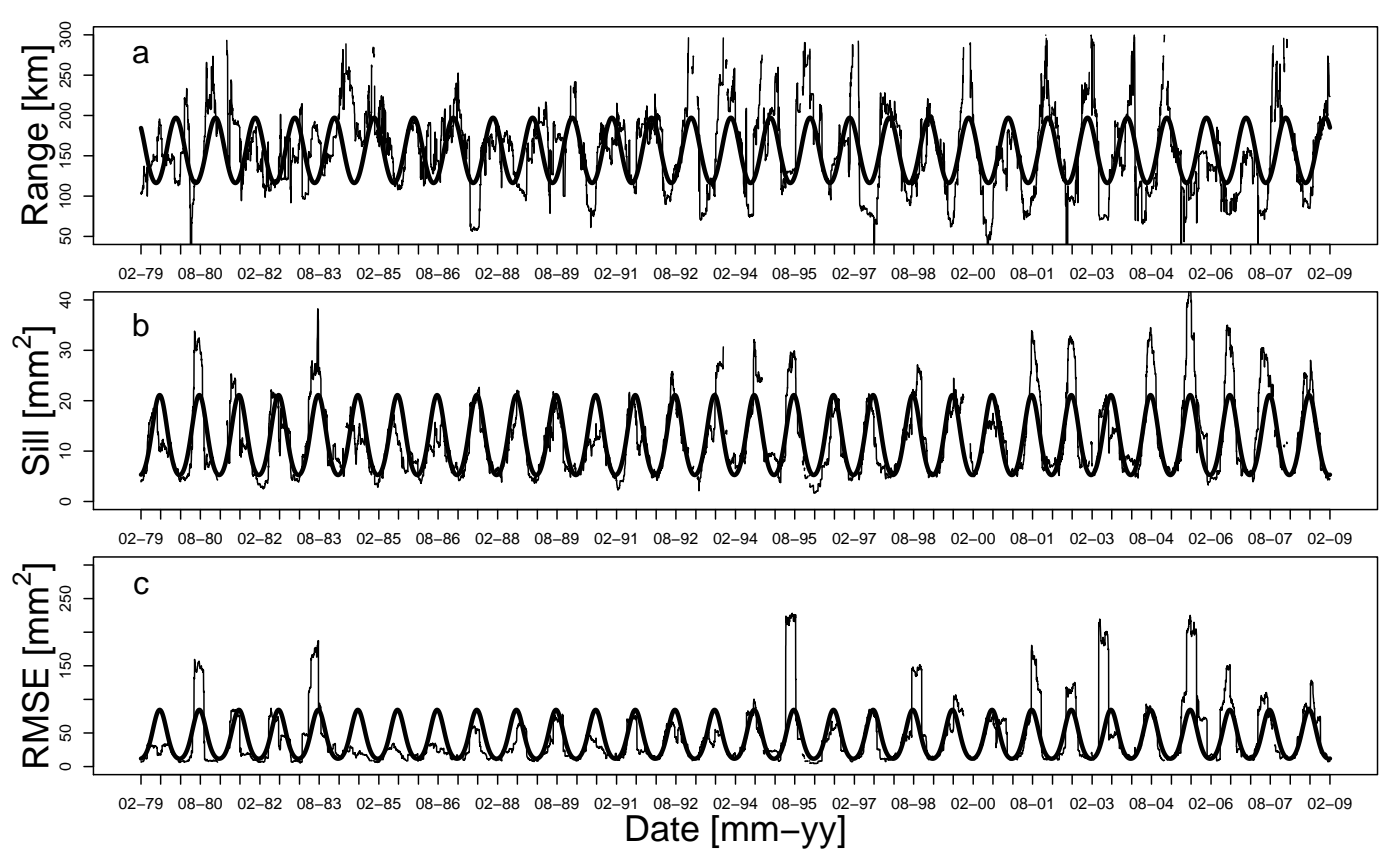

Fig. 5. Variation of 90-day moving window variogram parameters range (a), sill (b) and root mean squared error (c) for 30 years of daily rainfall data. The thin lines are the values found for each daily average and the bold lines are the cosines fitted through the data.

The sill reaches a maximum in August and a minimum in February. Where at first a low could be seen in the fitted cosine function of the range, there is now a peak in the sill. Again this can be attributed to the prevailing rain types during winter and summer. With convective rainfall in summer the variance between pairs will be high, but in winter, with similar rain rates over large distances, the daily rain sum will be quite similar, which results in a low variance. Unlike with the range exceptions do not noticeably occur when the fit is more linear than spherical around November. There is a shift of about 150 days between the fitted cosines of the sill and range. A shift of approximately half a year is to be expected, with the largest variance during late summer, when strong convective thunderstorms are most common, resulting in a large sill and small range, and the equal amounts of daily rain sums between pairs at longer distances in winter, resulting in a large range and a small sill. The fact that the shift is in fact only about 5 months can be partially explained by the transition period at the end of summer when the rain events become both larger in size and in amount. This causes both the sill and the range to increase. From September the scale of the rain events still grows, increasing the range, but the amounts of precipitation will start to decrease, lowering the sill.

\subsubsection{Seasonal root mean square error}

The sum of squared errors (SSE) is the sum of the squared differences between the empirical semi-variogram values and the fitted spherical variogram. Taking the root of the mean of
Table 2. Parameters of the sqrt-sqrt transformed cosine functions of the sill, range and root mean square errors for the fitted spherical variograms using the daily rain sums of 33 KNMI stations with a 90-day moving average window.

\begin{tabular}{lcrrr}
\hline & $1 / f$ & $A$ & $t_{0}$ & $x_{0}$ \\
\hline range & 365 & 1.30 & 2.5 & 19.77 \\
sill & 365 & 0.31 & 217.9 & 1.83 \\
RMSE & 365 & 0.61 & 212.0 & 2.52 \\
\hline
\end{tabular}

the SSE results in the root mean square error (RMSE). The RMSE is small for most of the year, but becomes large during summer, when measured amounts between gauges can strongly differ (Fig. 5c). The peaks occur mostly around August, but can be a month earlier or later. Again a cosine was fitted to the sqrt-sqrt transformed data and the corresponding parameter values can be found in Table 2 .

Like the sill and range, the difference between the low values in winter and the high values in summer can be explained by the type of precipitation during these times. It follows the shape of the sill closely (see Fig. 7b and c). As the variability between gauges tends to be small during winter, the squared differences from the fitted variogram will not be high. In summer the opposite occurs, which results in the high RMSE values. 

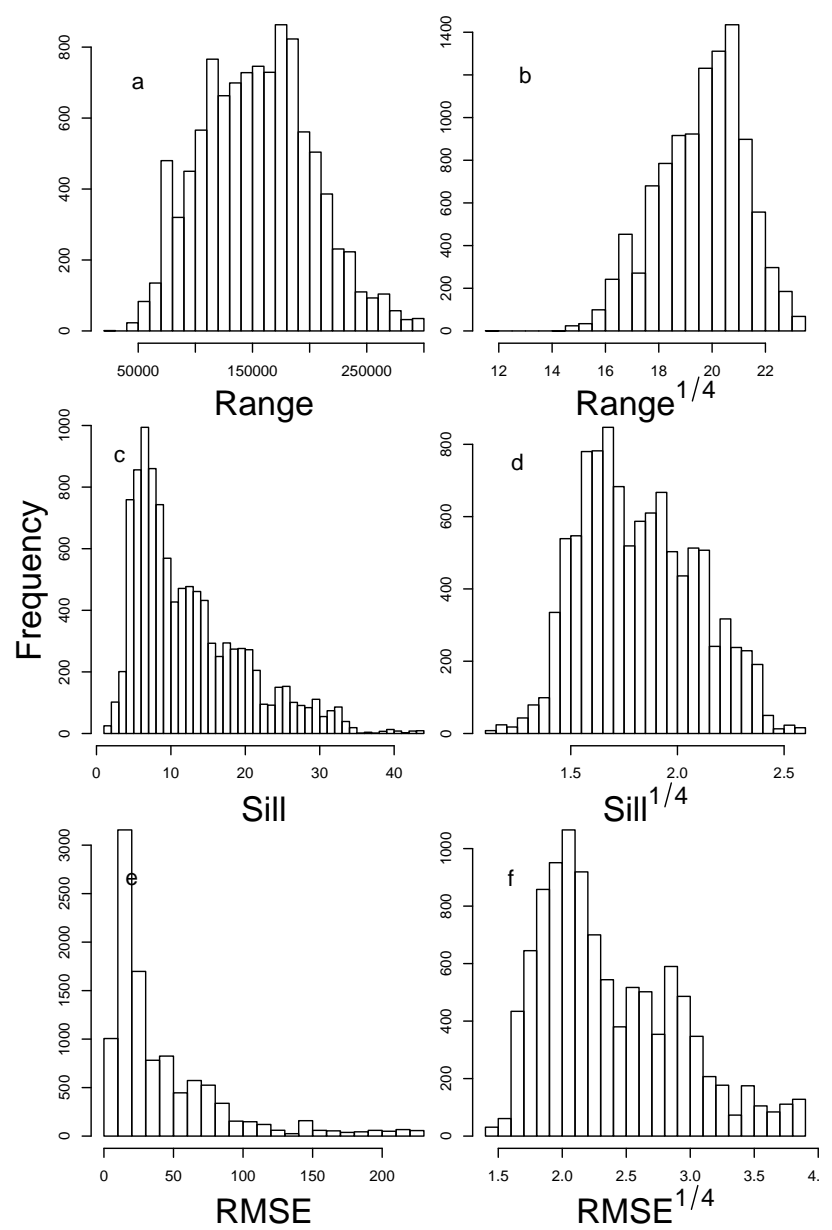

Fig. 6. Histograms of the range, sill, and RMSE before (a, c, and $\mathbf{e}$, respectively) and after (b, d, and $\mathbf{f}$, respectively) a sqrt-sqrt transform.

\subsubsection{Quality of the seasonal fits}

To assess the quality of the climatological models for range and sill these fits are compared with the actual range and sill values. This can be done by looking at anomalies. In Fig. 8 the climatological fits (the cosine functions fitted to the transformed range and sill values) are subtracted from the original fits (the range and sill values determined for each day separately), with ranges beyond $300 \mathrm{~km}$ removed, to find the anomalies for sill and range. For both the sill and range it is difficult to find a clear seasonal effect. In Fig. 9 the mean and standard deviation for each DOY over the 30 years shown in Fig. 8 are plotted. As can be seen in Fig. $8 \mathrm{f}$ the estimated range can differ up to $12 \%$ of the actual range, but the distribution is such that most values are concentrated around zero. For the sill the errors can be up to $14 \%$, but here the distribution is nearly uniform.
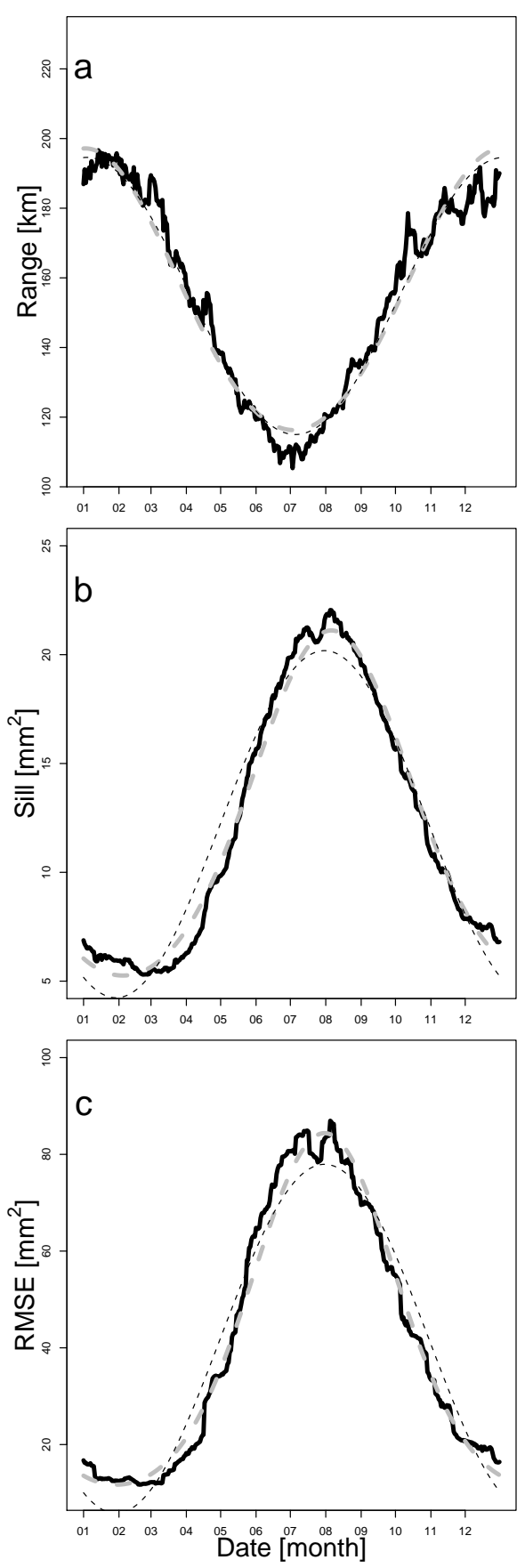

Fig. 7. Average daily variation of the range (a), sill (b) and root mean square error (RMSE) (c) for each day of year. The solid lines are the estimated values, the black dashed lines the cosine functions fitted on the normal data and the grey dashed lines the cosine functions fitted on the sqrt-sqrt transformed data.

To look in more detail at the difference between the actual range and sill values and the climatological fit the oneyear period between March 2004 and March 2005 is evaluated. In addition to the $33 \mathrm{KNMI}$ stations, 10 gauges from 

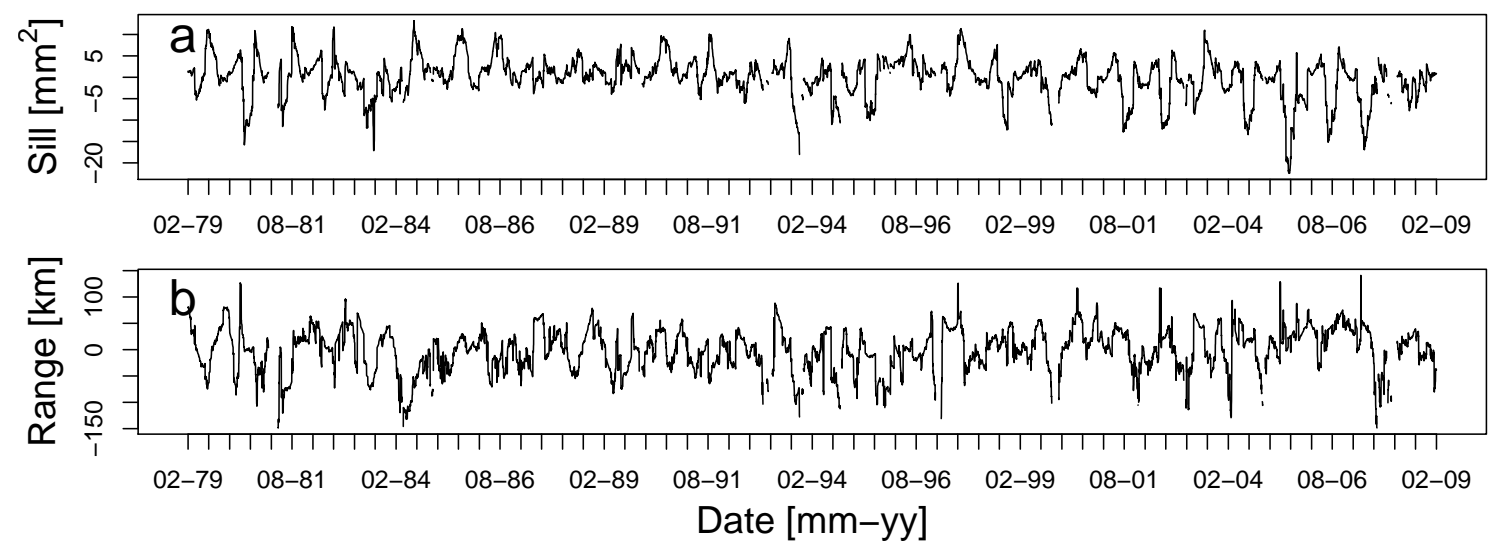

Fig. 8. The difference of the climatological fitted cosine and the actual values resulting in the anomaly of sill (a) and range (b).
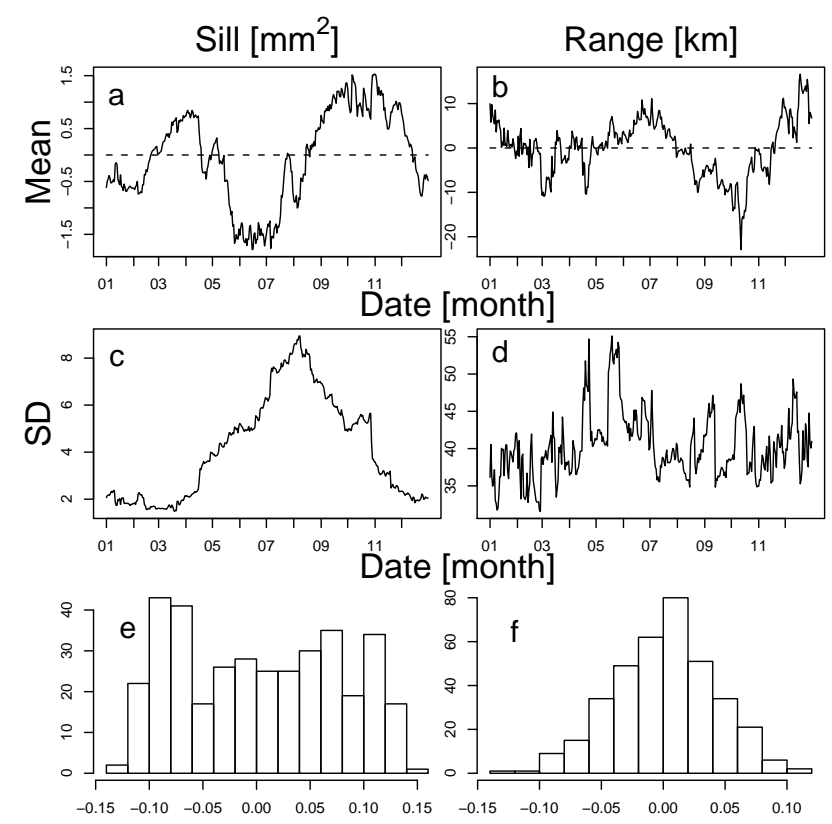

Fig. 9. Mean (a and b), standard deviation (SD; $\mathbf{c}$ and $\mathbf{d})$, and histograms (e and $\mathbf{f})$ of the sill (a, $\mathbf{c}$, and $\mathbf{e})$ and range (b, $\mathbf{d}$, and $\mathbf{f})$. Mean and SD are shown as functions of the time of year.

the dense rain gauge network around Cabauw are employed. This year has a fairly high sill and range and illustrates a case where the spherical variogram parameters differ fairly strongly from the climatological fit.

As can be seen from the fit of the sill, using KNMI and UU-WUR data, in Fig. 10a, the climatological fit (dashed cosine) for this year is fairly accurate, although its estimated peak during summer is smaller than that of the actual sill for this year (solid black line). The peak of the actual sill, while similar in shape, is smaller than the estimated sill using only the KNMI data (grey solid line) as well. The difference in the estimated parameters is caused by the rain gauge network
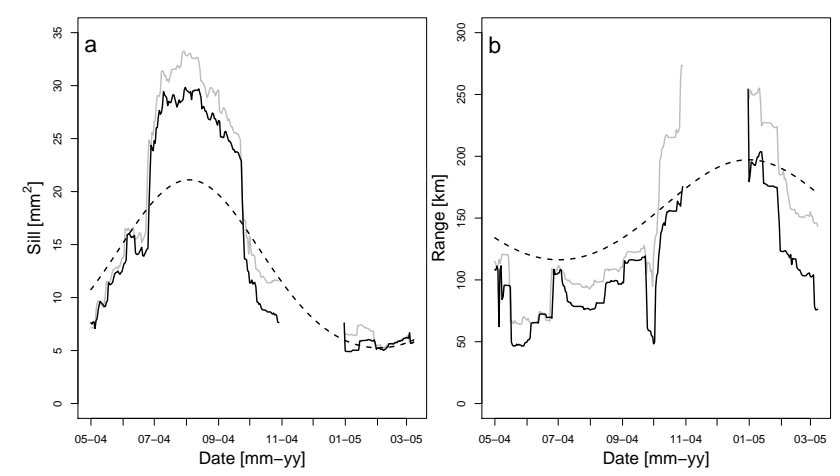

Fig. 10. Parameters of the fitted semi-variograms between March 2004 and March 2005. Left panel is sill and right panel is range of the fitted variogram. The dashed cosines are the estimates from the climatological variogram, the solid black lines are the fits for each day using all KNMI and UU-WUR data, and the solid grey lines are the fits for each day only using the KNMI data.

characteristics. This shows that the parameters are sensitive to the density and location of the data points. The exact sensitivity is beyond the scope of this paper. Note, however, that for both range and sill the effect of network characteristics is smaller than of the year-to-year variations. The comparison of range signals shown in Fig. 10b leads to conclusions similar to those for the sill (Fig. 10a), but with larger overall differences. The actual range has a much greater amplitude than the climatological range and also has a less smooth signal than that of the sill. This again illustrates that the range is less stable than the sill.

Figure 11 illustrates 4 cases throughout the year. In spring (a) the climatological fits and the actual sill and range values are similar, but the climatologies overestimate both sill and range slightly. The fit at short range does not seem to be ideal either, as all points up to $50 \mathrm{~km}$ lie above the fitted curve. Applying some sort of nested variogram with one fitted up to $50 \mathrm{~km}$ and one beyond could result in a better fit 


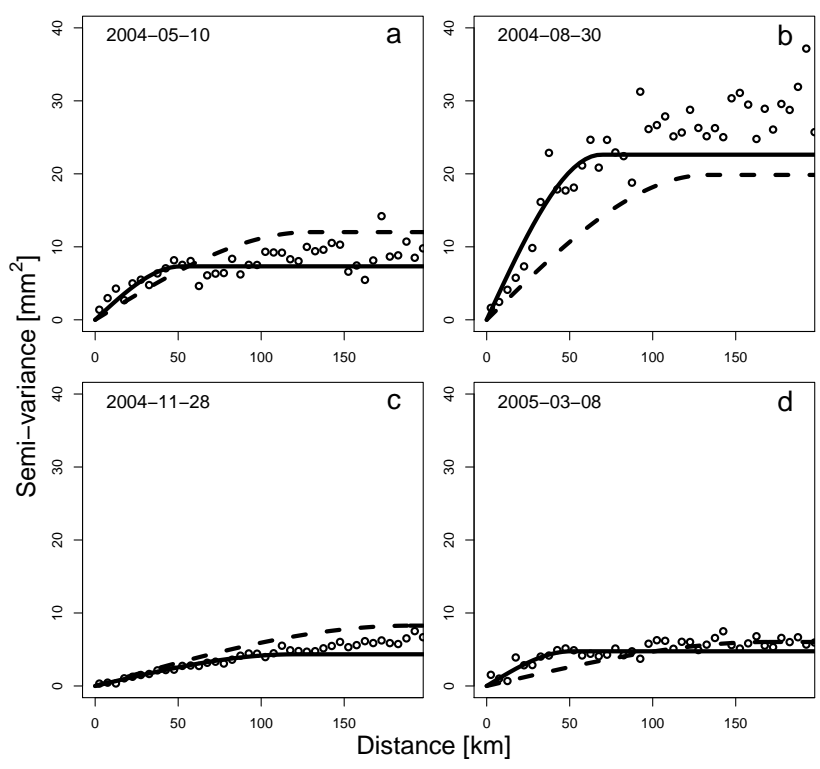

Fig. 11. Example of fitted semi-variograms for four days between March 2004 and March 2005. The solid line is the fitted variogram and the dashed line is the climatological variogram.

(e.g. Berne et al., 2004a). From this a better climatological fit might be estimated as well. The fits in summer (b) have a large variance and tend to have a fairly large scatter around the fit, resulting in a large RMSE (also see Fig. 5c). Due to the large variability of summer rain, where it is possible to have both strongly localized convective cells and more large scale stratiform rain, the variance between data-pairs varies quite a lot. As described in Sects. 5.2.1 and 5.2.2 this results in a large sill and a short range during summer. The exact timing of the maximum variance during summer varies from year to year and can even be absent or consist of several peaks.

Figure $11 \mathrm{c}$ illustrates the common problem of fitting rainfall variograms in The Netherlands around November, where often the fit to the data is nearly linear. This results in an estimated range far beyond the range of the furthest data-pair.

\subsection{Short range analysis}

For catchment hydrology in The Netherlands the relevant areas tend to be small and therefore an appropriate variogram at short ranges is important. As mentioned before, a lack of rain gauges for accurate estimates of catchment rainfall can be an important factor in hydrology and therefore it is important to find accurate variograms to interpolate between gauges or even extrapolate from a single gauge in a catchment.

Figure 12 illustrates the short range fit using 10 gauges from the dense rain gauge network around Cabauw mentioned in Sect. 2.2. As the semi-variance tends to be nearly linear up to this maximum distance of $10 \mathrm{~km}$ and the range of the variogram is far beyond this distance, the fit of the semi- variance illustrated in these figures is carried out through linear regression (see Eq. 4). In fitting the climatological variogram to the KNMI data the binning of data pairs was carried out using distance classes of $5 \mathrm{~km}$. For this short range this bin size is set to $500 \mathrm{~m}$. The top left panel shows the semivariance in spring when rain variability is already increasing to the summer maximum. The dashed line is the linear fit to the data of only the 10 gauges around CESAR (UU-WUR), the dotted line is the climatological fit, the solid line is the fit based on the $33 \mathrm{KNMI}$ gauges combined with the $10 \mathrm{UU}$ WUR gauges (KNMI-UU-WUR), and the dash-dotted line is the fit based on the $33 \mathrm{KNMI}$ gauges only (KNMI). It is clear that the actual semi-variances are higher than those resulting from the different variogram models. This is the case for most of May and June 2004. As can be seen in the top left panel of Fig. 11 the semi-variances for the first $50 \mathrm{~km}$ are indeed estimated to be lower than the values found for the UU-WUR gauges. As an accurate estimate of the variance at short distances is especially important for the purpose of small catchment hydrology it is clear that the fit found for the KNMI and UU-WUR gauges combined is not perfect. The KNMI-UU-WUR fit does perform better than the KNMI fit, but the effect is small. As mentioned before, applying nested variograms could solve the problem by merging a variogram fitted up to $50 \mathrm{~km}$ and one beyond $50 \mathrm{~km}$. For summer (top right panel) the slope of the actual fit and the fits found for UU-WUR, KNMI and KNMI-UU-WUR are very similar. While the RMSE is fairly large the fit of the longer range with only one spherical variogram appears to work rather well for the summer and autumn (bottom left panel). Finally, during winter the fit to the semi-variance is again larger than that of the other fits. Looking at the bottom right panel of Fig. 11, it can be concluded that this is caused by the same issue as was found for May and June 2004.

The results are summarized in Fig. 13 by estimating a linear slope for all fits for the first $10 \mathrm{~km}$. Here the issues with differences between fitting at only short distances and fitting over longer distances become more clear. During winter and spring the semi-variances at short ranges are larger than KNMI-UU-WUR variogram fit estimates and during summer and fall the values are fairly similar. Further differences are difficult to correct for due to annual differences that cannot be taken into account using a seasonal fit. Even though there are these year-to-year differences it was shown in Sects. 5.2.1 and 5.2.2 that the sill and range can be predicted well on average, with the exception of November, when the variogram tends to be linear.

\section{Conclusions and recommendations}

Variograms of daily rainfall are found to be strongly seasonal. Such seasonal fluctuations can be parameterized by very simple cosine functions. The average sill and range found from the fitted spherical variograms follow a cosine 


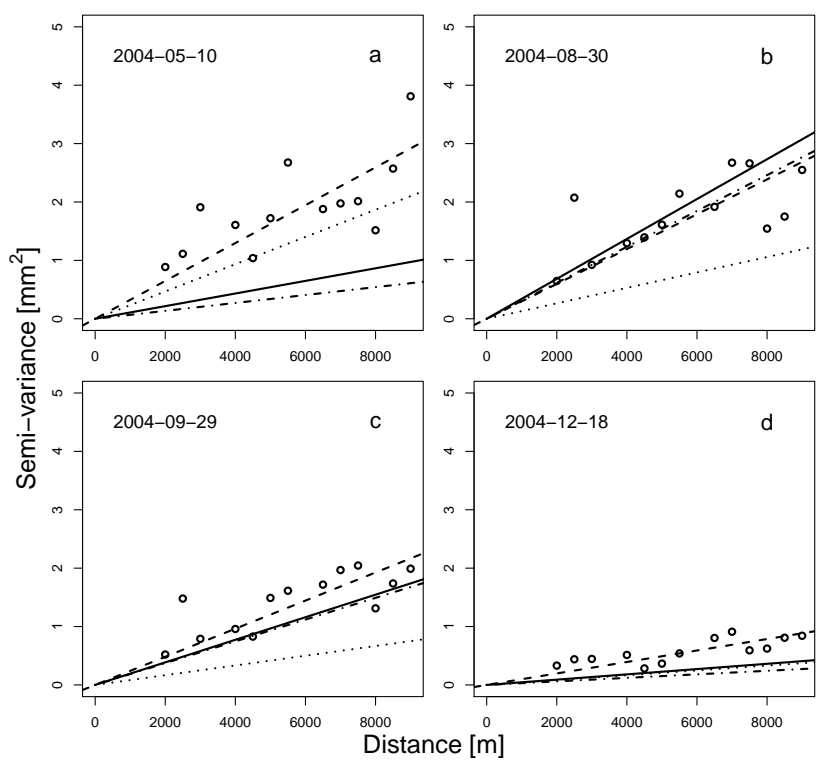

Fig. 12. Four examples of fitted variograms using only 10 gauges of the dense rain gauge network between March 2004 and March 2005. The dashed lines are the actual fits (UU-WUR), the dashdotted lines are the fits through the KNMI data (KNMI), the solid lines are the fits found in Sect. 5.2.4 from the combined KNMI and UU-WUR rain gauge data (KNMI-UU-WUR), and the dotted lines are the climatological fits.

function over the entire year with the exception of November, where the range often exceeds $300 \mathrm{~km}$. Year-to-year variations of the fitted spherical variogram parameters have been shown to exist, but they are found to be limited with respect to the amplitude of the seasonal signal. On average, the simple cosine parameterizations of the variogram sill and range have been shown to perform well.

For shorter ranges (up to $10 \mathrm{~km}$ ) the climatological fit follows the seasonal trend well, but underestimates compared to the fit for the year between March 2004 and March 2005. The difference between the short-range fit and long-range fit up to $10 \mathrm{~km}$ for the studied year is small during summer and autumn, but becomes stronger during winter and spring. This problem is due to the year-to-year variability in semi-variance and a possibly inappropriate variogram model (linear for November) and transform. Most of the difference can be explained by daily fluctuations, as the long and short ranges are mostly similar except for the aforementioned problems of variogram fitting during winter and spring, which could be solved by a nested variogram. In conclusion, while the climatological fit in this case underestimates the actual values for both long and short ranges, the semi-variance at short range could be estimated fairly well on average, as the climatological parameterization was shown to fit well for the 30 year data.

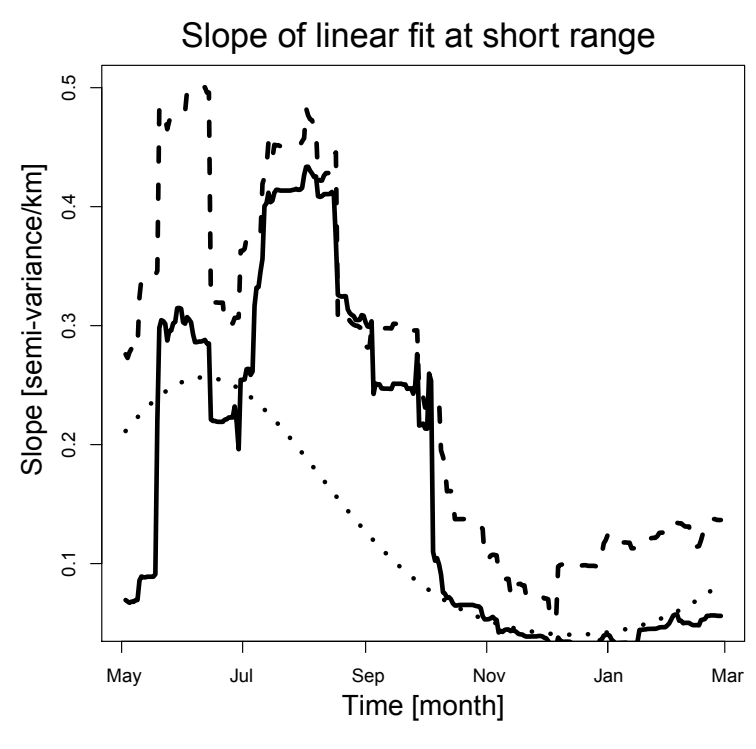

Fig. 13. Slope of the first $10 \mathrm{~km}$ of the variogram for the period between March 2004 and March 2005. The dashed line is the actual fit, the solid line is the fit found in Sect. 5.2.4 from the combined KNMI and UU-WUR rain gauge data and the dotted line the climatological fit.

While the results for long range climatological variograms are promising, the case study of short-range climatological variograms reveals issues that need to be resolved. Some recommendations for continued research would be to:

- use nested variograms for winter and spring periods;

- test variogram shape and stability for other time scales;

- evaluate the robustness of the climatological variogram by leaving some gauges out of the network and quantifying the differences (cross-validation), or alternatively comparing the estimated values with radar rainfall maps.

Acknowledgements. Financial support for this research was provided by The Netherlands Organization for Scientific Research (NWO) through grant EO-058.

Edited by: S. Attinger

\section{References}

Arnaud, P., Bouvier, C., Cisner, L., and Dominguez, R.: Influence of rainfall spatial variability on flood prediction., J. Hydrol., 260, 216-230, 2002.

van de Beek, C. Z., Leijnse, H., Stricker, J. N. M., Uijlenhoet, R., and Russchenberg, H. W. J.: Performance of high-resolution Xband radar for rainfall measurement in The Netherlands, Hydrol. Earth Syst. Sci., 14, 205-221, doi:10.5194/hess-14-205-2010, 2010. 
Bell, V. A. and Moore, R. J.: The sensitivity of catchment runoff models to rainfall data at different spatial scales, Hydrol. Earth Syst. Sci., 4, 653-667, doi:10.5194/hess-4-653-2000, 2000.

Berne, A., Delrieu, G., Andrieu, H., and Creutin, J.-D.: Influence of the vertical profile of reflectivity on radar-estimated rain rates at short time steps, J. Hydrometeorol., 5, 296-310, 2004a.

Berne, A., Delrieu, G., Creutin, J.-D., and Obled, C.: Temporal and spatial resolution of rainfall measurements required for urban hydrology, J. Hydrol., 299, 166-179, 2004b.

Buishand, T. A. and Velds, C. A.: Klimaat van Nederland 1. Neerslag en Verdamping, Tech. rep., Royal Netherlands Meteorological Institute, 1980 (in Dutch).

Buishand, T. A., de Haan, L., and Zhou, C.: On spatial extremes: With application to a rainfall problem, Ann. Appl. Stat., 2, 624642, doi:10.1214/08-AOAS159, 2008.

Buishand, T. A., Jilderda, R., and Wijngaard, J. B.: Regionale verschillen in extreme neerslag, Tech. rep., Royal Netherlands Meteorological Institute, 2009 (in Dutch).

Calder, I. R. and Kidd, C. H. R.: A note on the dynamic calibration of the tipping-bucket gauges, J. Hydrol., 39, 383-386, doi:10.1016/0022-1694(78)90013-6, 1978.

Cheng, K.-S., Lin, Y.-C., and Liou, J.-J.: Rain-gauge network evaluation and augmentation using geostatistics, Hydrol. Process., 22, 2554-2564, 2008.

Ciach, G. J.: Local random errors in tipping-bucket rain gauge measurements, J. Atmos. Oceanic Technol., 20, 752-759, 2003.

Cressie, N. A.: Statistics for spatial data, Wiley, NY, revised edn., 1993.

Creutin, J.-D., Delrieu, G., and Lebel, T.: Rain measurement by raingauge-radar combination: a geostatistical approach, J. Atmos. Oceanic Technol., 5, 102-115, 1986.

Daly, C., Gibson, W. P., Taylor, G. H., Dogget, M. K., and Smith, J. I.: Observer bias in daily precipitation measurements at United States cooperative network stations, B. Am. Meteorol. Soc.,88, 899-912, doi:10.1175/BAMS-88-6-899, 2007.

Delrieu, G., Hucke, L., and Creutin, J.-D.: Attenuation in rain for X- and C-band weather radar systems: sensitivity with respect to the drop size distribution, J. Appl. Meteorol., 38, 57-68, doi:10.1175/1520-0450, 1999.

Diggle, P. J. and Ribeiro Jr., P. J.: Model-based geostatistics, Springer, NY, 2007.

Ensor, L. A. and Scott, M. R.: Statistical charisteristics of daily precipitation: comparison of gridded and point datasets, J. Appl. Meteorol. Clim., 47, 2468-2476, doi:10.1175/2008JAMC1757.1, 2008.

Guillot, G. and Lebel, T.: Approximation of Sahelian rainfall fields with meta-Gaussian random functions - Part 2: parameter estimation and comparison to data, Stoch. Environ. Res. Risk Assess., 13, 113-130, 1999.

Haberlandt, U.: Geostatistical interpolation of hourly precipitation from rain gauges and radar for a largescale extreme rainfall event, J. Hydrol., 332, 144-157, doi:10.1016/j.jhydrol.2006.06.028, 2007.

Habib, E., Krajewski, W. F., and Kruger, A.: Sampling errors of tipping bucket rain gauge measurements, J. Hydrol. Eng., 6, 159166, doi:10.1061/(ASCE)1084-0699(2001)6:2(159), 2001.

Habib, E., Boone, F. L., and Grachel, J.: Validation of NEXRAD multisensor precipitation estimates using an experimental dense rain gauge network in south Louisiana, J. Hydrol., 373, 463-478,
2009.

Hartwig, F. and Dearing, B. E.: Exploratory data analysis, Sage Publications, Newberry Park, CA, 1979.

Hitschfeld, W. and Bordan, J.: Errors inherent in the radar measurement of rainfall at attenuating wavelengths, J. Meteorol., 11, 58-67, 1954.

Humphrey, K. D., Istok, J. D., Lee, J. Y., Hevesi, J. A., and Flint, A. L.: A new method for automated dynamic calibration of tipping-bucket rain gauges, J. Atmos. Oceanic Technol., 14, 1513-1519, doi:10.1175/1520-0426, 1997.

Joss, J. and Waldvogel, A.: Comments on "Some observations on the Joss-Waldvogel rainfall disdrometer”, J. Appl. Meteorol., 16, 112-113, 1977.

Kirstetter, P. E., Delrieu, G., Boudevillain, B., and Obled, C.: Toward an error model for radar quantitative precipitation estimation in the Cevennes-Vivarais region, France, J. Hydrol., 394, 28-41, doi:10.1016/j.jhydrol.2010.01.009, 2010.

Knox, R. and Anagnostou, E., N.: Scale interactions in radar rainfall estimation uncertainty, J. Hydrol. Eng., 9, 944-953, 2009.

Krajewski, W. F.: Co-kriging radar-rainfall and raingage data, J. Geophys. Res., 92, 9571-9580, 1987.

Krajewski, W. F. and Smith, J. A.: Radar hydrology: rainfall estimation, Adv. Water Resour., 25, 1387-1394, doi:10.1016/S03091708(02)00062-3, 2002.

Krajewski, W. F., Ciach, G. J., McCollum, J. R., and Bacotiu, C.: Initial validation of the Global Precipitation Climatology Project monthly rainfall over the United States, J. Appl. Meteorol., 39, 1071-1086, 2000.

Leijnse, H., Uijlenhoet, R., and Stricker, J. N. M.: Hydrometeorological application of a microwave link: 2. Precipitation, Water Resour. Res., 43, W04417, doi:10.1029/2006WR004989, 2007.

Leijnse, H., Uijlenhoet, R., van de Beek, C. Z., Overeem, A., Otto, T., Unal, C. M. H., Dufournet, Y., Russchenberg, H. W. J., Figueras i Ventura, J., Klein Baltink, H., and Holleman, I.: Precipitation measurement at CESAR, the Netherlands, J. Hydrometeorol., 11(6), 1332-1339, doi:10.1175/2010JHM1245.1, 2010.

Li, B., Eriksson, M., Srinivasan, R., and Sherman, M.: A geostatistical method for Texas NexRad data calibration, Environmetrics, 19, 1-19, 2008.

Marsalek, J.: Calibration of the tipping-bucket raingage, J. Hydrol., 53, 343-354, 1981.

Marshall, J. S., Hitschfeld, W., and Gunn, K. L. S.: Advances in radar weather, Adv. Geophys., 2, 1-56, 1955.

Marzoug, M. and Amayenc, P.: A class of single- and dualfrequency algorithms for rain-rate profiling from a spaceborne radar. Part I: Principle and test from numerical simulations, J. Atmos. Oceanic Technol., 11, 1480-1506, 1994.

Nour, M. H., Smith, D. W., and Gamal El-Din, M.: Geostatistical mapping of precipitation: implications for rain gauge network design, Water Sci. Tech., 53, 101-110, 2006.

Olsson, J., Berggen, K., Olofsson, M., and Viklander, M.: Applying climate model precipitation scenarios for urban hydrological assessment: A case study in Kalmar City, Sweden, Atmos. Res., 92, 364-375, 2009.

Overeem, A., Buishand, A., and Holleman, I.: Extreme rainfall analysis and estimation of depth-duration-frequency curves using weather radar, Water Resour. Res., 45, W10424, doi:10.1029/2009WR007869, 2009.

Papamichail, D. M. and Metaxa, I. G.: Geostatistical analysis of 
spatial variability of rainfall and optimal design of a rain gauge network, Water Resour. Manag., 10, 107-127, 1996.

Schleiss, M. A., Berne, A., and Uijlenhoet, R.: Geostatistical simulation of two-dimensional fields of raindrop size distributions at the meso-gamma scale, Water Resour. Res., 45, 1-10, doi:10.1029/2008WR007545, 2009.

Schuurmans, J. M., Bierkens, M. F. P., Pebesma, E. J., and Uijlenhoet, R.: Automatic prediction of high resolution daily rainfall fields for multiple extents: the potential of operational radar, J. Hydrometeorol., 8, 1204-1224, doi:10.1175/2007JHM792.1, 2007.

Shumway, R. H. and Stoffer, D. S.: Time series analysis and its applications - with R examples, Springer, NY, 2nd edn., 2006.

Sieck, L. C., Burges, S. J., and Steiner, M.: Challenges in obtaining reliable measurements of point rainfall, Water Resour. Res., 43, W01420, doi:10.1029/2005WR004519, 2007.

Smith, J. A., Baeck, M. L., Morrison, J. E., Sturdevant-Rees, P., Turner-Gillespie, D. F., and Bates, P. D.: The regional hydrology of extreme floods in an urbanizing drainage basin, J. Hydrometeorol., 3, 267-282, 2002.

Smith, J. A., Baeck, M. L., Meierdiercks, K. L., Nelson, P. A., Miller, A. J., and Holland, E. J.: Field studies of the storm event hydrologic response in an urbanizing watershed, Water Resour. Res., 41, W10413, doi:10.1029/2004WR003712, 2005.

Tetzlaff, D. and Uhlenbrook, S.: Significance of spatial variability in precipitation for process-oriented modelling: results from two nested catchments using radar and ground station data, Hydrol. Earth Syst. Sci., 9, 29-41, doi:10.5194/hess-9-29-2005, 2005.

Uijlenhoet, R.: Precipitation physics and rainfall observation. Chapter 4, in: Climate and the Hydrological Cycle (M.F.P. Bierkens, A.J. Dolman en P.A. Troch, editors), IAHS Special Publications 8, IAHS Press, Wallingford, 2008.
Vaes, G., W. P. B. J.: Areal rainfall correction coefficients for small urban catchments, Atmos. Res., 77, 48-59, 2005.

Velasco-Forero, C. A., Sempere-Torres, D., Cassiraga, E. F., and Gomez-Hernandez, J. J.: A non-parametric automatic blending methodology to estimate rainfall fields from rain gauge and radar data, Adv. Water Resour., 32, 986-1002, 2009.

Villarini, G. and Krajewski, W. F.: Empirically-based modeling of spatial sampling uncertainties associated with rainfall measurements by rain gauges, Adv. Water Resour., 31, 1015-1023, doi:10.1016/j.advwatres.2008.04.007, 2008.

Villarini, G. and Krajewski, W. F.: Review of the different sources of uncertainty in single-polarization radar-based estimates of rainfall, Surv. Geophys., 31, 107-129, doi:10.1007/s10712-0099079-x, 2010.

Villarini, G., Mandapaka, P. V., Krajewski, W. F., and Moore, R. J.: Rainfall and sampling uncertainties: a rain gauge perspective, J. Geophys. Res., 113, D11102, doi:10.1029/2007JD009214, 2008.

Villarini, G., Smith, J. A., Baeck, M. L., Sturdevant-Rees, P., and Krajewski, W. F.: Radar analyses of extreme rainfall and flooding in urban drainage basins, J. Hydrol., 381, 266-286, 2010.

Wauben, W.: KNMI contribution to the WMO Laboratory Intercomparison of Rainfall Intensity Gauges, KNMI internal report, available at: http://www.knmi.nl/ $\sim$ wauben/Sensor/TR287.pdf, 2006.

Witter, J. V.: Heterogeneity of Dutch rainfall, Ph.D. thesis, Wageningen University, 204 pp., 1984. 